\title{
O Conceito de Vocábulo na Obra de Mattoso Câmara
}

\author{
(The Concept of Word in Mattoso Câmara)
}

Margarida BASÍLIO

$(P U C-R J)$

\begin{abstract}
This paper deals with Prof. Mattoso Câmara Junior's concept of word and its identification in the structure of Brazilian Portuguese. Initiallly, I briefly survey the main problems concerning the concept of word in structuralism and its origin; in the central part of the article, I focus on Mattoso Câmara's proposals in his main works, situating them in the context of the development of Linguistics in Brazil; I then present the author's view of the question of word compounding. The last part of the article summarizes his main contributions towards establishing the concept and defining processes for the identification of the word in Portuguese.
\end{abstract}

KEY-WORDs: Word; Compounds; Mattoso Câmara Júnior; Brazilian Portuguese.

RESUMO: O presente trabalho aborda na obra de Mattoso Câmara Júnior a questão do conceito de palavra e sua identificação na estrutura da Lingua Portuguesa. Colocamos, de início, um breve histórico do problema da conceituação de palavra no estruturalismo e seus antecedentes; na parte central do artigo, focalizamos as propostas de Mattoso Câmara Júnior em seus principais trabalhos, situadas no contexto do desenvolvimento da Lingüística no Brasil; em seguida, apresentamos a visão do Mestre sobre a questão das composiçoes vocabulares. A parte final do artigo resume as principais contribuições de Câmara Júnior para a conceituaşão e identificação do vocábulo na Língua Portuguesa. PaLAVRas-CHave: Palavra; Vocábulo; Composição; Mattoso Câmara Júnior; Língua Portuguesa.

\section{Introdução}

O presente artigo é um tributo à memória do Prof. Mattoso Câmara Júnior, certamente o nome mais relevante na história da lingüística em nosso país. 
Conheci o Prof. Mattoso Câmara como professor de Introdução à Lingüística Geral, quando cursava o último semestre de Letras Clássicas da PUC-RJ, em 1967. No ano seguinte, ingressando no Mestrado em Lingüística do Programa Unificado de Pós-Graduação em Lingüística do Museu Nacional, em 1968, ainda teria eu o privilégio, por mais dois semestres, de ter o Professor Mattoso Câmara como professor, nos cursos de História da Lingüística e Estrutura da Língua Portuguesa.

$\mathrm{Na}$ época, ele nos apresentava as últimas versões de suas análises e descrições do português, que posteriormente vieram a constituir o inacabado e fundamental Estrutura da Lingua Portuguesa; o precursor Problemas de Lingüística Descritiva; e o precioso História da Lingüiśstica.

Não há outro epíteto para Mattoso Câmara senão O Grande Mestre. O domínio absoluto de todos os temas que abordava, a farta erudição, os comentários fundamentados e bem elaborados, a solidez da argumentação; e também os detalhes pitorescos, um leve tom de humor, pequenas pausas amenas quando via que não podíamos mais acompanhar o ritmo das reflexões teóricas. Sim, Mattoso Câmara não foi apenas o grande pioneiro da Lingüística no país; foi, também, um professor perfeito.

Mudaram-se os paradigmas, a Lingüística teve no Brasil um desenvolvimento ímpar, juntamente com a evolução planejada do sistema de pósgraduação no país; alargaram-se os domínios da investigação, novos métodos de análise são privilegiados. Mattoso Câmara passou de precursor a clássico. E sua obra mantém a relevância de sempre.

Como especialista em Morfologia e herdeira convicta do legado mattosiano de intensa dedicação à descrição e ensino da língua portuguesa, escolhi, dentre as inúmeras contribuições de Mattoso Câmara para a Lingüística e a descrição de nossa língua, abordar em sua obra a questão do conceito de palavra e sua identificação na estrutura da língua portuguesa.

$\mathrm{O}$ artigo está dividido em três partes. Na primeira, coloco os antecedentes que determinam o problema do conceito de palavra no estruturalismo, descrevo o problema e resumo o posicionamento de Saussure e Bloomfield. Na segunda, abordo o conceito de palavra em Mattoso Câmara Júnior. Na terceira, analiso como o Mestre tratou da questão da composição na Língua Portuguesa. 


\section{O conceito de palavra no Estruturalismo}

\subsection{Antecedentes}

Se observarmos nossas gramáticas, constataremos que o conceito de palavra não é abordado, mas tomado implicitamente. Isto se verifica porque, nas gramáticas tradicionais, o modelo subjacente é o modelo 'Palavra e Paradigma', em que a palavra é considerada como a unidade mínima de análise lingüística. Nesse modelo, a forma das palavras apresenta um esquema relativamente fixo de variações para a expressão de categorias acidentais, o paradigma. Temos, portanto, substantivos classificados em declinações e verbos em conjugações, cada um(a) com seu paradigma correspondente. As gramáticas do português não apenas apresentam o termo explícito 'paradigma' no tratamento dos verbos, mas também a organização implícita, que entende a palavra como a unidade mínima de análise lingüística.

A conceituação de palavra, no entanto, passou por diferentes abalos em vários momentos da história da lingüística e continua sendo discutida até hoje. Aqui vamos nos deter nas questões que surgem com o advento do estruturalismo. Para isto, entretanto, é necessário traçarmos um panorama de sua evolução sobretudo a partir do século XIX.

Ainda que gramáticos antigos tenham intuído a distinção entre derivação e flexão, conforme observa Mattoso Câmara (1970: 71), ou que termos como radical e afixos tenham sido utilizados já há alguns séculos, apenas no século XIX, com o desenvolvimento da Lingüística Histórica, passa a haver uma preocupação geral com a estrutura interna da palavra. É nesta época que o termo morfologia passa a ser utilizado abrangendo a flexão e a derivação.

De fato, o século XIX se caracteriza inicialmente pelo desenvolvimento do método histórico-comparativo, com o qual se pretendia estabelecer a relação genética entre línguas; e pelo subseqüente desenvolvimento do método histórico, através do qual se estabelecia a evolução fonética a partir de formas básicas teorizadas como ancestrais. Ora, dadas as profundas modificações ocorridas sobretudo em situações de juntura, que dificultavam o estabelecimento de correspondências sistemáticas, os comparatistas precisavam proceder à análise da estrutura interna da palavra e recuperar 
os elementos formativos, a serem comparados em diferentes línguas. A manipulação desta estruturação, ao lado da comparação de sistemas morfológicos que pressupunha a flexão, muito cedo levou à necessidade de se delimitar e nomear os dois campos da morfologia, a flexão e a derivação.

Podemos observar, então, já na literatura correspondente ao método comparativo e ao método histórico, a ascensão da relevância dos elementos formativos em detrimento da palavra como um todo; as comparações e relações sistemáticas se estabelecem em termos de raízes lexicais e terminações flexionais e não em termos de uma unidade que já não pode mais ser definida como elemento mínimo da análise lingüística, embora, naturalmente, o reconhecimento da unidade palavra continue sendo feito sem maiores problemas.

\subsection{O conceito de palavra no estruturalismo: o problema}

A questão da definição e estatuto da palavra passa a ter mais peso no estruturalismo americano, dada a primazia do morfema como unidade morfológica. É de se observar, no entanto, que esta proposição deve ser considerada como conseqüência, e não causa, do abandono do princípio da palavra como elemento mínimo da análise lingüística, uma vez que este abandono já havia sido efetuado, em termos concretos, pela prática do método comparativo. O deslocamento da palavra do centro da língua para uma área cinzenta, assim como a eleição do morfema como elemento básico da morfologia não são propriamente invenções do estruturalismo, como se poderia pensar, mas aplicações do princípio sincrônico sobre uma situação de fato legada pelo período do estudo histórico de línguas.

Mais especificamente, depois de um século de análises baseadas no desmembramento da palavra e focalização em suas partes constituintes, a palavra monolítica estava definitivamente enterrada. Por outro lado, o princípio estruturalista e a concentração na descrição de línguas clamavam por critérios de classificação; a emergência do morfema é, neste contexto, praticamente inevitável. Além disso, também a língua escrita foi para segundo plano no estruturalismo, passando-se a considerar a cadeia fônica como base da análise lingüística, sobretudo no estruturalismo americano, concentrado fundamentalmente na descrição de línguas indígenas desconhecidas, ou seja, línguas cujas unidades lexicais relevantes o lingüista ignorava. 
Surge, portanto, não apenas uma questão teórica, mas uma dificuldade metodológica: que unidades deverão ser consideradas palavras, a partir de que critérios, como definir e justificar as marcas pertinentes. A célebre definição de Bloomfield, de base distribucionalista, é uma tentativa relativamente bem sucedida de resolver ao mesmo tempo os problemas teórico e metodológico. Mas, no estruturalismo descritivo, o pilar do modelo clássico de descrição gramatical já havia sido desfeito, de sorte que os limites da palavra passaram a constituir um problema, e seu estatuto como unidade lingüística passou a ser questionado.

É de se observar que as grandes dificuldades em relação à definição de palavra no estruturalismo americano, tanto em termos de fixarmos seus limites, quanto em relação a estabelecermos seu estatuto na estrutura lingüística, embora legada a situação problemática pelos desenvolvimentos da lingüística no século XIX, é inerente à problemática da Lingüística Americana na época, dado o descritivismo impulsionado pela necessidade de descrição das línguas indígenas americanas, por um lado, e, por outro, dada a interpretação de estrutura como 'estrutura do enunciado' por Bloomfield, em oposição ao estruturalismo sistêmico mentalista de Saussure.

De fato, o estruturalismo europeu não apresenta os problemas com que se depara Bloomfield porque os europeus não têm línguas indígenas a descrever e Saussure está interessado na faculdade de linguagem e na língua como um depósito de signos, no "tesouro depositado na mente dos falantes”, este tesouro que é um fato social. Assim, Saussure se preocupa com a questão da oposição e do sistema de valores; sua unidade básica é o signo. Claro, tanto palavras quanto morfemas são signos; o problema da definição da palavra permanece, mas não é uma questão crucial e urgente para o estruturalismo europeu, que está preocupado com as relações entre os signos na mente dos falantes e não com as relações em presença que se manifestam na fala. Esta diferença se reflete nos focos privilegiados pelos dois grandes nomes-símbolo do estruturalismo lingüístico.

\subsection{O conceito de palavra em Saussure e Bloomfield}

Em "Um conjunto de postulados para a ciência da Linguagem", Bloomfield procura dar definições absolutamente explícitas para os termos 
da lingüística descritiva. A definição de palavra que ele propõe é de cunho puramente distribucional.

De acordo com Bloomfield (1978[1926]), uma forma é um traço vocal recorrente que tem significado e todo enunciado é inteiramente constituído de formas. Dentro deste quadro, define-se a palavra através das seguintes afirmações: (a) um $X$ mínimo é um $X$ que não consiste inteiramente de X's menores; (b) uma forma que pode ser um enunciado é livre. Uma forma que não é livre é presa; ${ }^{1}$ e (c) uma forma livre mínima é uma palavra. Para Bloomfield, uma palavra é, portanto, uma forma que pode ser enunciada sozinha (com significado), mas não pode ser analisada em partes que podem (todas elas) ser enunciadas sozinhas (com significado).

Em Language (1933), Bloomfield apresenta a mesma definição, embora dentro de um quadro diferente: uma forma livre composta inteiramente de duas formas livres menores é um sintagma. A palavra é a forma livre que não é um sintagma. Mais especificamente, a palavra é uma forma livre não composta inteiramente por formas livres menores. Bloomfield define, pois, a palavra como a forma livre mínima. Acrescenta ele que, na medida em que apenas as formas livres podem se constituir isoladamente num enunciado, a palavra, unidade mínima enquanto forma livre, exerce um papel importante em nossa atitude em relação à língua: a palavra é a menor unidade do discurso. Ou seja, a palavra é a menor unidade lingüística de que facilmente temos consciência.

Saussure (1916:122), por outro lado, problematiza os métodos correntes de delimitação: “...basta pensar na palavra cheval ('cavalo') e em seu plural chevaux. Diz-se correntemente que são duas formas da mesma palavra; todavia, tomadas na sua totalidade, são duas coisas bem diferentes, tanto pelo sentido como pelos sons.". Saussure prossegue dizendo que a tentativa de equiparar unidades concretas a palavras nos leva a um dilema, o de ignorar a relação evidente que une, por exemplo, cheval a chevaux e dizer que são palavras diferentes; ou então, estabelecer uma abstração que reúne as formas de uma palavra.

Vemos, portanto, que, enquanto Bloomfield identifica palavras por seu papel na estrutura do enunciado, Saussure (1916:123) se preocupa em

\footnotetext{
Assim, o livro, o homem são formas livres; -ndo (como em escrevendo), -or (como em escritor) são formas presas.
} 
identificar palavras no sistema de valores mental: "Uma teoria assaz difundida pretende que as únicas unidades concretas sejam as frases: só falamos por frases, e depois delas extraímos as palavras. Em primeiro lugar, porém, até que ponto pertence a frase à língua? Se é coisa exclusiva da fala, não poderia nunca passar por unidade lingüística."

Os dois conceitos refletem dois pontos de enfoque do estruturalismo: a estrutura do enunciado e a estrutura do sistema lingüístico; e dois pontos cruciais de desafio a definições: a relação lexema-vocábulo-palavra e a questão da identificação da palavra na corrente da fala e sua distinção com a palavra enquanto unidade lingüística.

\section{O conceito de palavra em Mattoso Câmara}

Em Princípios de Lingüística Geral, Mattoso Câmara, no capítulo sobre unidades significativas, coloca logo de início um problema fundamental relacionado ao conceito de palavra no estruturalismo:

Esta falta corriqueira de coincidência entre o elemento na fonação e o elemento na fala tem levado alguns lingüistas a negarem que o vocábulo significativo, ou vocábulo propriamente dito, seja entidade natural lingüística. Tendem a considerá-lo qualquer coisa de convencional, imposto à nossa consciência pelas formalidades do ensino e da língua escrita. O elemento significativo seria, a rigor, exclusivamente a própria frase. (Mattoso Câmara 1967: 86)

Mattoso Câmara nega a adequação desta proposta, assumindo a posição de Saussure, segundo a qual apenas o vocábulo é puramente um elemento da língua. Afirma, ao contrário, que é exatamente a falta de coincidência entre o vocábulo fonético e o vocábulo como elemento significativo que nos permite aceitar a realidade lingüística do vocábulo: "relacionamse entre si os elementos idênticos existentes em múltiplas frases, e desta comparação emerge o modelo mental chamado vocábulo, com individualidade ao mesmo tempo significativa e formal. Em outros termos, a noção do vocábulo assenta na identificação parcial que se faz dentro da diferença global das frases." (Mattoso Câmara 1967:87). Vemos, pois, que Câmara abraça o ângulo saussuriano.

Observa ele, entretanto, que este critério seria o mesmo para afixos e desinências; e passa, então, a estabelecer a necessária delimitação, que valida 
o raciocínio enquanto aplicado à especificidade da palavra, explicitando três diferenças básicas: A primeira é a colocação de Bloomfield de que a palavra, ao contrário dos afixos, ocorre isoladamente, constituindo uma forma livre. A segunda é a mobilidade de posição (anteposição ou posposição), possível nos clíticos mas não nos afixos. E a terceira diferença, de caráter fundamental: o vocábulo "tem incontestável autonomia ou individualidade formal, porque não é condicionado pela forma particular do vocábulo a que se adjunge."

É a partir dessa enumeração de fatores de diferenciação que Mattoso propõe a sua divisão tripla, em substituição à proposta bloomfieldiana:

Chegamos assim a 3 tipos de formas: 1) forma presa, que só aparece ligada a outra e por ela condicionada; 2) forma dependente, que nunca aparece isolada, mas pode aparecer ligada a outra que não é aquela que a condiciona, quando entre ela e a sua condicionante se intercalam livremente outras formas; 3) forma livre, que aparece não raro isolada. (Mattoso Câmara 1967:88).

O conceito de palavra em Mattoso Câmara se reveste de fundamental importância, dado que Mattoso é o lingüista responsável pela formação de inúmeros lingüistas no país, e, em especial, lingüistas que se formaram no período do estruturalismo; é ele que nos traz, não apenas o estruturalismo em lingüística, mas, de modo fundamental, a aplicação do estruturalismo lingüístico à descrição da morfologia do português.

A preocupação de Mattoso em relação à descrição da língua portuguesa é dupla e a situação é mais complexa, dado o momento histórico de prevalência de uma tradição gramatical no ensino da língua, confrontado com a exigência de introdução da disciplina Lingüística nos cursos de Letras e, portanto, na formação de todos os professores da área.

Referindo-se à dicotomia saussuriana sincronia/diacronia e constatando a prioridade da lingüística descritiva sobre os estudos históricos, Mattoso assim descreve a situação em relação à Língua Portuguesa em Problemas de Lingüistica Descritiva:

A língua portuguesa, no entanto, tem ficado à margem dêsses propósitos descritivos. A lingüística em Portugal e no Brasil tem sido entendida, de preferência, como fundamentalmente histórica. Em regra, em matéria de sincronia, o que se tem feito em Portugal e no Brasil é o ensino gramatical como "arte de falar e escrever corretamente”. A lingüística só trata da história da língua e a descrição é substituída por um código normativo, com vistas à prática escolar. (Mattoso Câmara 1969: 9). 
A extrema preocupação de Mattoso Câmara em colocar os produtos da lingüística descritiva a serviço do conhecimento da língua portuguesa leva ao primeiro problema fundamental encontrado em relação à palavra: o fato de que "toda e qualquer descrição da língua portuguesa leva em conta a existência do vocábulo", embora não se tenha cogitado, nas abordagens tradicionais, de "explicar e claramente definir em que consiste ele" (Mattoso Câmara 1969: 34). A falha, naturalmente, provém do fato de que nossas gramáticas tomam por base a língua escrita, na qual a palavra é definida pelos espaços em branco, conforme determinado pelo sistema gráfico.

Mattoso introduz, então, a distinção entre duas unidades diferentes sob o mesmo nome: o vocábulo fonológico, correspondente a uma "divisão espontânea na cadeia de emissão vocal”, e o vocábulo formal ou mórfico, "quando um segmento fônico se individualiza em função de um significado específico que lhe é atribuído na língua”, fazendo a crucial colocação de que, embora relacionadas, essas entidades podem não coincidir (Mattoso Câmara 1967:34).

No Dicionário de Lingüística e Gramática, Mattoso define palavras como "vocábulos providos de significação externa, concentrada no radical; noutros termos, vocábulos providos de semantema". Nesta definição, introduz-se a preocupação do mestre com o problema terminológico: a utilização do termo vocábulo de um ponto de vista mais técnico, reservando-se palavra para as unidades significativas.

Em Princípios de Lingüística Descritiva, Mattoso esclarece o princípio norteador da divisão na emissão da cadeia da fala, afirmando que os vocábulos fonológicos não se separam por pausas na corrente da fala: "Em português, o vocábulo fonológico depende da força de emissão das suas sílabas. A verdadeira marca da delimitação vocabular é a pauta prosódica" (Mattoso Câmara 1969: 35-36). Ou seja, na língua portuguesa o vocábulo fonológico é definido pela pauta prosódica, determinada pelo acento tônico.

Na verdade, a tarefa de Mattoso Câmara é complexa, na medida em que se trata não apenas de direcionar o estudo e ensino da língua para uma abordagem descritiva, em oposição a uma tradição que privilegia o estudo histórico, mas direcioná-lo a uma base oral em oposição a uma tradição de base escrita. Ora, no caso da palavra, como ele salienta logo de início, esta abordagem instaura problemas de definição totalmente estranhos à abor- 
dagem anterior. Pois, como ele observa, "a língua escrita não tem em vista o vocábulo fonológico e sim o vocábulo mórfico ou formal." (Mattoso Câmara 1969: 36).

Mas o elemento fundamental para a definição do âmbito da Morfologia é o vocábulo formal, caracterizado por Bloomfield como uma forma livre mínima, ou a unidade a que se chega, quando não é possível nova divisão em duas ou mais formas livres. Daí a importância do conceito de forma dependente: "Conceitua-se assim uma forma que não é livre, porque não pode funcionar isoladamente como comunicação suficiente; mas também não é presa, porque é suscetível de duas possibilidades para se disjungir da forma livre a que se acha ligada" (Mattoso Câmara 1969: 37). Com isto, o vocábulo se redefine como forma não presa mínima, considerando-se como vocábulos formais tanto formas livres quanto formas dependentes; em conseqüência, incluem-se como vocábulos formais os artigos, preposições, conjunções e pronomes clíticos, que só ocorrem em função de outras formas, não podendo, portanto, ocorrer isoladamente, mas tendo mobilidade de posição em relação às formas das quais dependem.

É de se notar, portanto, a extrema adequação e elegância da proposta de Mattoso, que permite assim compatibilizar com a abordagem tradicional um critério descritivo estruturalista, através de uma pequena modificação, a caracterização de vocábulo mórfico que obedece também aos padrões do sistema gráfico do português.

Que se esclareça, contudo, que a análise não é apenas uma maneira alternativa de se colocar uma situação conciliatória entre a preocupação com o ensino descritivo e o realismo da necessidade do ensino tradicional da gramática: sobre este efeito desejável e conseguido, a classificação proposta, que redefine as unidades anteriormente propostas por Bloomfield, responde de maneira bem mais cabal à situação estrutural dos elementos envolvidos na língua portuguesa.

Definem-se assim como vocábulos formais, para Mattoso Câmara, a grande maioria dos vocábulos gráficos: nomes e verbos, mas também artigos, preposições, etc.; excetuando-se os pronomes clíticos, graficamente marcados como tais.

Os vocábulos formais têm em comum o fato de não serem formas presas, isto é, afixos; a definição de Bloomfield é tomada, portanto, do 
lado oposto, e interpretada não em seu aspecto sintático, mas reinterpretada em seu correlato morfológico: a rigidez da construção é característica das construções morfológicas, que envolvem radicais e afixos, todos formas presas, ou seja, formas que isoladamente não podem constituir enunciados.

\section{Composições de vocábulos em Mattoso Câmara}

Uma vez conceituado o vocábulo formal, em oposição tanto ao vocábulo fonológico, quanto ao vocábulo gráfico, vejamos os problemas em relação a diferentes composições vocabulares.

Mattoso assinala de início que as palavras tradicionalmente consideradas compostas por justaposição correspondem a uma situação que é o reverso da verificada nas chamadas formas dependentes: neste tipo de palavra composta, temos dois vocábulos fonológicos que constituem um único vocábulo formal.

Assim, segundo ele, guarda-chuva e grande chuva têm a mesma pauta acentual. O que caracteriza os compostos por justaposição, no entanto, é a rigidez que a construção adquire: embora os elementos componentes de guarda-chuva mantenham sua identidade semântica reconhecível, o conjunto não pode se desligar de um todo denotativo; e, por outro lado, a construção petrifica seus elementos, de modo a tornar qualquer interferência impossível. Assim, enquanto ainda podemos falar de uma grande e estrondosa chuva, ou das grandes chuvas de verão, não podemos falar de *guarda-muita-chuva, ou daqueles *guardam-chuvas.

Um outro problema que Mattoso aborda é o das locuções, em que temos dois vocábulos formais. Assim, ele considera que os conceitos podem coincidir nos casos de substantivos compostos por justaposição, por aí termos também dois vocábulos formais; ou nos advérbios formados pela sufixação de -mente a adjetivos, no caso de -mente ser interpretado como forma livre; e nos tempos compostos dos verbos. Mas ressalta que não se trata de expressões equivalentes, na medida em que o conceito de locução se refere apenas ao plano mórfico, podendo a locução ser definida como "o uso sistemático como unidade formal de dois vocábulos mórficos" (Mattoso Câmara 1969:38).

Uma definição alternativa para locução aparece no Dicionário de Lingïística e Gramática: "Reunião de dois vocábulos que conservam indivi- 
dualidade fonética e mórfica, mas constituem uma unidade significativa para determinada função", que é interessante cotejarmos com a definição de composição: "Formação de uma palavra pela reunião de outras, cujas significações se complementam para formar uma significação nova". Naturalmente, formularemos a questão de o que distinguiria a locução da palavra formada por composição.

É, portanto, interessante observarmos que, em Princípios de Lingüística Descritiva, Mattoso continua suas reflexões sobre a locução reconhecendo como locuções seqüências como chapéu de sol, estrada de ferro, tenho de sair; e observa que os conceitos de justaposição e locução coincidem em substantivos compostos por justaposição como guarda-chuva, rosa-chá, etc. Prossegue Mattoso afirmando que "[p]or falta de uma definição adequada para vocábulo e da confusão, a seu respeito, entre plano mórfico e plano fonológico, há na nossa tradição gramatical uma teoria de vocábulos compostos, que é inteiramente falsa" (Mattoso Câmara 1967:38).

Refere-se ele à classificação dos processos de composição em justaposição, aglutinação e prefixação. De fato, a aglutinação é um fenômeno fonológico, passível, aliás, de ocorrer em qualquer construção morfológica (cf., por exemplo, planalto de plano + alto e roseira, de rosa +eira) e não um processo de composição. Do mesmo modo, configura-se a justaposição, segundo Mattoso Câmara, quando, na reunião de duas formas, mantém-se a respectiva identidade fonológica, como em pós-moderno, bipocritamente ou porta-bandeira. Portanto, mais uma vez, trata-se da classificação de uma oposição de situações fonológicas em casos de junção de formas, que, portanto, não deveria ser usada para a classificação de tipos de composição.

O caso da prefixação é diferente, tanto porque não se trata de uma configuração fonológica, quanto pelo fato de gerar uma polêmica interessante, referente à distinção entre formas derivadas e compostas na descrição das estruturas morfológicas do português.

Ainda em Princípios de Lingüística Descritiva, Mattoso (1969:39) diz que a prefixação é um processo de formação de palavras que deve ser considerado como composição, porque os prefixos apresentam o valor significativo das preposições, ainda que alguns sejam apenas alomorfes e outros não se usem como preposições. Assim, por exemplo, ex-, provindo da preposição latina, apenas ocorre como prefixo em português; o prefixo supermantém a forma latina, mas a preposição em português se transformou em sobre; e assim por diante. 
No Dicionário de Lingüística e Gramática, Mattoso diz, sobre o prefixo:

Assim se chama o afixo que vem na parte inicial do vocábulo. Na língua portuguesa, o prefixo, que é a variante presa das formas dependentes chamadas preposições, cria uma nova significação externa para a palavra a que se adjunge, e por isso se deve considerar o processo da prefixação como uma modalidade da composição vocabular. (Mattoso Câmara 1997[1977]).

Vemos, portanto, que Mattoso considera fundamental como critério para a determinação das palavras compostas o critério semântico, ao contrário de outros estudiosos, quer tradicionais, quer estruturalistas, que estabelecem como critério fundamental a combinação de palavras ou radicais. Segundo ele, os sufixos, ao contrário dos prefixos, não apresentam significado.

Mattoso não ignora, entretanto, o aspecto do caráter vocabular ou não dos elementos num processo de formação. Assim, ele define a derivação como processo em que o elemento formador não corresponde a um vocábulo e introduz uma idéia apenas acessória. Afirma, então, que no caso do português os elementos com essas características se pospõem ao semantema, enquanto os prefixos, antepostos, alteram fundamentalmente a significação do semantema e correspondem a preposições, no português e no latim.

Naturalmente, a questão do grau de relevância de cada fator, a autonomia vocabular e o papel e teor da modificação introduzida no semantema pelo elemento formador são difíceis de determinar. Mattoso está ciente das alternativas de análise; no verbete derivação, esclarece que "[os prefixos] ... são por isso incluídos de preferência no processo da composição..., embora muitos gramáticos incluam sufixos e prefixos na derivação, que passa a ser sufixal e prefixal (...)". Mas, ainda que outros fatores de ordem estrutural possam fundamentar descrições alternativas, é crucial fazermos jus à intuição do Mestre, que nos aponta o inegável fator da maior pertinência semântica do prefixo em sua combinação com o semantema, em comparação com as construções derivadas sufixais. ${ }^{2}$

\footnotetext{
2 Cf., por ex., a hipótese de Bybee (1985) sobre o maior valor semântico nos elementos mais internos à estrutura morfológica.
} 


\section{Considerações finais}

A contribuição de Mattoso Câmara na solução de problemas e desvendamento de mistérios em relação à identificação do conceito de palavra é considerável, não apenas por sua análise de todos os problemas e pontos de divergência em relação a uma abordagem tradicional do estudo da língua frente a novas proposições descritivas, mas também por sua ponderada adequação e adaptação de conceitos teóricos e descritivos ao material de nossa língua a ser reanalisado.

Coloco em especial relevo a sua reformulação da proposição bloomfieldiana de definição distribucional da palavra, introduzindo o conceito de forma dependente para abarcar formas como artigos, preposições, clíticos em geral; e sua perspicácia na análise das confluências entre locução e composição, objeto de debates ainda hoje em relação à delimitação das unidades lexicais.

E-mail:marbas@centroin.com.br

\section{REFERÊNCIAS}

BAsílio, Margarida. 1999. Introdução: questões clássicas e recentes na delimitação de unidades lexicais. In: M. Basilio (org.) A Delimitação de Unidades Lexicais. PaLavra 5, Volume Temático I. Rio de Janeiro: PUCRIO.

Bloomfield, Leonard. 1933/1935. Language. London: George Allen \& Unwin Ltd.

1978[1926]. Um Conjunto de Postulados para a Ciência da Linguagem. In: M. Dascal (org.) Concep̧ões Gerais da Teoria Lingüística. São Paulo: Global.

Bybee, Joan. 1985. Morphology. Amsterdam: John Benjamins.

Mattoso Câmara Jr., J. 1967. Princípios de Lingüística Geral. 4a. ed. Rio de Janeiro: Livraria Acadêmica.

1969. Problemas de Lingǘstica Descritiva. Petrópolis: Vozes.

1970. Estrutura da Língua Portuguesa. Petrópolis: Vozes.

1997[1977]. Dicionário de Lingüística e Gramática. 18a. ed. Petrópolis: Vozes.

Saussure, Ferdinand de. 1916. Curso de Lingüística Geral. (Trad. de Antonio Chelini, José Paulo Paes e Izidoro Blikstein). São Paulo: Cultrix. 